\title{
O slogan publicitário: algumas estratégias argumentativas
}

\author{
Edson Santos Silva / Wilma Rigolon
}

\section{Resumo:}

$\mathrm{Na}$ sociedade de consumo, a publicidade ocupa lugar de destaque, pois apresenta uma linguagem elaborada que visa influenciar as pessoas na compra de produtos e/ou idéias, bem como pode proporcionar mudança de comportamento. Assim, para que o consumidor seja mais atento e crítico, deve conhecer alguns elementos de persuasão que a publicidade usa para conquistar seu público. Neste trabalho, serão analisadas algumas técnicas discursivas presentes na linguagem publicitária, no caso, o «slogan» publicitário de natureza verbal, evidenciando a força persuasiva do enunciado proposto.

\section{Palavras Chave:}

slogan; persuasão; estratégias argumentativas

\begin{abstract}
:
In the consuming society, publicity has its own place once it presents a complex language which aims to influence people in buying products and/or ideas, as well as providing behavior change. Thus to be more attentive and critical, the consumer has to know some persuasive elements which publicity uses to reach their public. In this work, we will analyze some discursive techniques common in the language of publicity - in fact, the verbal publicity slogan - making evident the persuasive strength (power) of the proposed statement.
\end{abstract}

\section{Keywords:}

slogan; persuasion; discursive techniques

Na sociedade de consumo, a publicidade ocupa lugar de destaque, pois apresenta uma linguagem elaborada que visa influenciar as pessoas na compra de produtos e/ou idéias, bem como pode proporcionar mudança de comportamento. Assim, para que o consumidor seja mais atento e crítico, deve conhecer alguns elementos de persuasão que a publicidade usa para conquistar seu público. Neste trabalho, serão analisadas algumas técnicas discursivas presentes na linguagem publicitária, no caso, o «slogan» publicitário de natureza verbal, evidenciando a força persuasiva do enunciado proposto. A linguagem, presente em várias situações, é a mediação necessária entre o homem e a realidade natural e social, e é através dela, enquanto interação, modo de produção social e suporte das representações ideológicas, que se chega às práticas discursivas.

Interagir pela linguagem significa realizar uma atividade discursiva: dizer alguma coisa a alguém, de uma determinada forma, num determinado contexto histórico e em determinadas circunstâncias de interlocução. As escolhas feitas ao produzir um discurso não são aleatórias, mas decorrentes de algumas condições em que é realizado, ou seja, quando um sujeito interage verbalmente com outro, o discurso se organiza a partir de suas finalidades e intenções.

A partir da constatação de que a linguagem é uma atividade social, um processo de produção de sentido numa dada formação discursiva, pode-se asseverar que o ato de argumentar constitui o ato lingüístico fundamental, e que qualquer discurso (ação verbal) veicula uma ideologia e uma intenção, que estão presentes no ato da 
enunciação.

Essa visão da linguagem enquanto enunciação tem como precursor o filósofo soviético Mikhail Bakhtin, que já no final da década de 20 opunha sua visão de linguagem à do lingüista genebrino Ferdinand de Saussure, na medida em que este considerava a fala como fenômeno individual e o sistema lingüístico como social, e aquele se recusava a separar o individual do social. Embora ambos concebam a língua como fato social cuja existência funda-se nas necessidades de comunicação, a visão saussuriana postula a linguagem como um sistema abstrato de formas, e a bakhtiniana concebe a língua como algo concreto.

Para Bakhtin, a linguagem é fenômeno social, histórico e ideológico; além disso, estabelece o enunciado como unidade básica de análise lingüística, atribuindo à enunciação um papel privilegiado para a compreensão de qualquer ato de comunicação. A linguagem é um lugar de interação, já que através da enunciação se realiza a intersubjetividade humana, que apresenta um caráter dialógico.

Se comunicar é agir sobre o outro, quando se comunica não se pretende apenas que o sujeito receba e compreenda a mensagem, mas que esta seja aceita. Portanto, argumentar é um procedimento lingüístico que visa persuadir, fazer aceitar o que é comunicado, levar a crer no que é dito e a fazer o que é proposto. A argumentação já era objeto de estudo na Antigüidade Grega, pois o homem sempre usou a linguagem não apenas para se comunicar ou informar, mas, sobretudo, para agir e persuadir. Posteriormente, esse estudo foi desacreditado, porque se limitava à classificação das figuras de estilo. Com o aparecimento da Pragmática, atrelou-se à Retórica, quando o discurso e a argumentação passaram a ocupar lugar de destaque nas pesquisas acerca da linguagem.

Modernamente, a obra de Charles Perelman (1970) reabilitou a teoria da argumentação, considerada como "o emprego de técnicas discursivas visando a provocar ou a incrementar a adesão dos espíritos às teses apresentadas ao seu assentimento", caracterizando-se como um ato de persuasão. Portanto, a linguagem é não só meio de comunicação, mas, também, um instrumento de ação, uma estratégia que conduz ao ato de persuadir, ou ainda, segundo Ducrot (1977), "o uso da linguagem é inerentemente argumentativo".

De acordo com o exposto, a linguagem pode ser considerada como uma forma de ação dialógica dotada de intencionalidade, que atua sobre o comportamento do outro, levando-o a partilhar seus juízos. Esse poder argumentativo, que visa persuadir, evidencia-se, especialmente, na linguagem publicitária, cujo intuito é vender imagens, serviços e idéias, atingindo o enunciatário, de modo a conduzi-lo a uma significação específica que é, muitas vezes, a de comprar o produto que se apresenta, ou mudar de atitude diante do que é oferecido através da comunicação.

No discurso publicitário há uma articulação de recursos visuais, sonoros e técnicas que construirão uma rede de ações, cujo efeito na recepção poderá ser de caráter consumista ou ideológico. O que conta, no texto publicitário, é o que está subjacente, implícito, conotado. Assim, “a força persuasiva não está apenas nas palavras que fazem referência ao produto, ou suas qualidades, mas também nos signos dirigidos diretamente ao consumidor virtual, do qual se espera determinado comportamento" (REBOUL, 1977). Qualquer anúncio, quando realizado, funciona como discurso porque é destinado a comunicar e divulgar informações que são seu conteúdo significativo por meio de uma estrutura codificada que o autor cria e organiza, operando, então, como informativo e persuasivo.

A mensagem publicitária não é apenas demonstração de imaginação criadora de idéias, mas, também, arte e técnica aplicadas na solução de problemas. Suas finalidades são informar alguém sobre algum produto ou serviço, persuadir as pessoas a tomarem decisões e fazer agir para conseguir novas atitudes. Tais características podem ser observadas na linguagem do «slogan» publicitário, que consiste numa fórmula curta, resumida e incisiva, que exerce, através do impacto que causa, uma pressão no enunciatário, ou seja, no 
consumidor, para que compre o produto. É um tipo de comunicação unilateral, estabelecida por um enunciador (empresa) para um enunciatário (público consumidor), porém, sem reciprocidade, pois não há troca de papéis. A comunicação só se realizará, efetivamente, se a recepção da mensagem tiver uma incidência observável sobre o comportamento do público, isto é, se for constatada a venda do produto em questão.

O termo «slogan»vem do gaélico, língua do povo celta, e significa "grito de guerra", "«slugh-ghairm»". Por volta do século XIV, os ingleses adotaram o termo para transformá-lo, no século XIX, em divisa de partido e, a seguir, em palavra de ordem eleitoral. Os americanos deram ao termo o sentido de divisa comercial, e é com esse sentido publicitário que a palavra chegou à França, por volta de 1927, adquirindo, em seguida, um sentido político. Assim, foi usada por pregoeiros ambulantes, nas legendas e nas insígnias, até se identificar com anúncios de jornais, revistas e outdoors.

Com o desenvolvimento dos meios de comunicação de massa, o «slogan» tornou-se um instrumento de propaganda, uma arma cujo alcance ultrapassou os limites de um grupo restrito. Seu significado varia de autor para autor; entretanto, é sempre um ato verbal construído linguisticamente por uma frase ou um grupo de frases: "Frase concisa, de fácil percepção e memorização, que resume as características de um produto ou serviço, ou uma de suas qualidades ou ponto de venda, usada e repetida inalternadamente nos anúncios de uma firma” (MICHAELIS, 1998: 1954).

Para definir o slogan, convém determinar o seu estatuto gramatical. Aparentemente, trata-se de uma frase, ou de um grupo de frases, pois do ponto de vista semântico, acredita-se que o slogan se baste a si mesmo e que pode ser verdadeiro ou falso. Enfim, chamo de slogan a uma fórmula concisa e marcante, facilmente repetível, polêmica e freqüentemente anônima, destinada a fazer agir as massas tanto pelo seu estilo, quanto pelo elemento de autojustificação, passional ou racional, que ele comporta (REBOUL, 1977).

Buscando pontos comuns nas conceituações apresentadas, fica evidente, à primeira vista, que o «slogan» é uma frase ou grupo de frases de natureza breve. É uma espécie de fórmula polêmica endereçada ao público, e sua força reside tanto em sua forma quanto em seu sentido. Através dessa brevidade, o «slogan» chama a atenção não sobre si mesmo, mas sobre o que diz ou dá a entender, conseguindo o seu objetivo: persuadir o sujeito à compra do produto ou à mudança de comportamento.

Costuma-se atribuir ao «slogan» algumas funções básicas, como fazer aderir, prender a atenção e resumir. A função primordial é sempre a de "fazer vender" um produto, não comportando apenas uma indicação, um conselho, mas certa pressão; as palavras não desempenham só a função de informar ou prescrever, mas, sobretudo, de convencer, mandar fazer. Seja qual for sua função aparente, a real não está no seu sentido, mas no impacto; não está no que ele quer dizer, mas no que ele quer fazer.

Especificamente em publicidade, a grande parte dos «slogans» tenta agradar, como uma maneira de persuadir, provocando uma necessidade ou uma preferência. Partindo do princípio aristotélico de que o objetivo de toda comunicação é a persuasão, constata-se que o «slogan» publicitário usa esse procedimento muitas vezes até dissimulando seu poder persuasivo, com o uso de alguns procedimentos lingüísticos responsáveis pela intencionalidade do enunciado.

Para observar o funcionamento concreto de um gênero discursivo, será analisado o discurso publicitário, não só porque a interação interlocutiva é explícita, mas também porque ocupa largo espaço no cotidiano. Dentro do gênero escolhido, delimitou-se o «slogan» publicitário de natureza verbal, cuja intenção é atingir o enunciatário de modo a comprar o produto. Para tanto, serão explicitados alguns procedimentos lingüísticos 
responsáveis pela intencionalidade argumentativa dos enunciados. Tais procedimentos serão divididos em dois grupos:

\section{Procedimentos argumentativos}

- utilização de operadores argumentativos indicadores das conclusões para as quais os enunciados apontam;

- uso de enunciados de um campo lexical de determinada formação discursiva na qual o enunciatário se situa como agente;

- escolha intencional de modalizadores que permitam ao leitor a maior ou menor adesão ao que é dito;

- elaboração discursiva que possibilite a leitura de informações implícitas e subentendidas, transformando o enunciatário em cúmplice;

- preferência por expressões que mudem de sentido de uma formação discursiva para outra, configurando casos de polissemia e de ambigüidade;

- citação de autoridade;

- utilização de indicadores atitudinais;

- uso do dêitico «você», para que o leitor seja sujeito na formação discursiva;

- emprego de polifonia.

\section{Procedimentos retórico-estilísticos}

- predomínio das figuras de linguagem e de pensamento;

- uso de recursos sonoros;

- utilização de «détournement» e jogo de palavras.

1) "Para uma pessoa ocupada como você, o tempo voa. Só que a gente pode voar ainda mais rápido." (Rio Sul - Varig ).

O anúncio acima apresenta os seguintes recursos retórico-estilísticos: presença de metáforas (o tempo voa - a gente pode voar) e de metonímias (a gente - empresa). Através do uso de linguagem coloquial (você - a gente) cria-se uma familiaridade entre o enunciador e o enunciatário. Quanto aos subentendidos, destacam-se: 
- o tempo voa para as pessoas ocupadas

- você é ocupado

- logo, você não tem tempo. Conseqüentemente, o tempo voa para você.

- A Rio-Sul voa.

- As outras empresas também voam.

- Só que a Rio-Sul voa mais rápido do que as outras.

O uso do dêitico «você» permite uma interpelação mais direta, influenciando o enunciatário. É o processo de assujeitamento, segundo Althusser (1974), em que o indivíduo passa a sujeito assujeitado e situado numa mesma formação discursiva, identificando-se, ideologicamente, com a comunidade e as instituições (no caso, a Rio- Sul). O uso da locução conjuntiva «só que», equivalendo ao «mas», operador argumentativo, introduz uma perspectiva que não é a do primeiro enunciador, mas a de um outro enunciador (polifonia) para o qual o enunciado tende (o vôo mais rápido da Rio-Sul ).

Tal enunciado é reforçado, também, pela presença de dois modalizadores:

- «pode»: modalidade pragmática que denota capacidade;

- «ainda»: cuja enunciação aponta para o futuro enquanto possibilidade de realização do objetivo da empresa: voar mais rápido do que as outras.

Os índices atitudinais são, lingüisticamente, marcados pela presença do adjetivo «ocupada» e do advérbio «rápido», que caracterizam uma avaliação subjetiva do enunciador, reforçando a intenção de convencer o leitor das qualidades da empresa.

Através desta breve análise, afiança-se a função persuasiva da linguagem publicitária, em que os recursos lingüísticos têm o poder de influenciar o pensamento das pessoas, fazendo-as comprar o produto ou mudar de atitude.

2) "Se é Bayer, é bom."

Numa primeira leitura, verifica-se que a mensagem é facilmente desvendada. Através de um processo metonímico (Bayer) anuncia-se um produto (inseticida); a aliteração (repetição da consoante sonora bilabial B) enfatiza a força do «slogan»: ser facilmente repetível.

Numa segunda leitura, o enunciado abre-se a múltiplas possibilidades, não só enfatizando a importância do produto, como também a sua compra, cuja sugestão é feita através de um processo persuasivo manifestado pelo uso de um mecanismo coesivo de condicionalidade explícita: «se». 
- condição: se (o produto) é Bayer,

- condicionado: (o produto) é bom.

Por meio desse mecanismo, ficam evidentes alguns subentendidos:

- só os produtos da marca Bayer são bons;

- os produtos de outra marca não são bons;

- logo, compre só os produtos da Bayer.

A força desse «slogan» está no não-dito e na citação de autoridade: se é Bayer é bom; é a marca Bayer que se liga a uma formação discursiva que consegue criar no enunciatário a ilusão de ser o locutor. Além disso, percebe-se que ele manifesta suas intenções e sua atitude perante o enunciado que produz, empregando modalizadores e índices atitudinais: «Se é Bayer é bom»; é uma modalidade assertiva que está condicionada à marca (Bayer), e o uso do adjetivo «bom» indica uma avaliação apreciativa de valor moral ou estético que também se refere à condicionalidade.

Em suma, a marca Bayer é utilizada no lugar do produto, reiterando a concisão do «slogan», como uma maneira de persuadir o leitor a comprar o inseticida somente da marca em questão

3) "Merthiolate - você pode precisar."

Neste «slogan», novamente constata-se que é a marca (Merthiolate) que anuncia o produto (antisséptico), caracterizando um processo metonímico. Em seguida, há a presença do dêitico «você», representando o enunciatário. Esse mecanismo visa fazer com que o interlocutor anônimo seja interpelado para que se identifique como sendo, de fato, o «você» da interpelação. Dessa maneira, o leitor afetado passa a ser o sujeito nessa formação discursiva. O uso do auxiliar modal «pode» orienta o enunciatário na interpretação do conteúdo temático do «slogan», insinuando uma obrigação social do consumidor, apresentando-a como necessária. É uma modalidade pragmática, que denota necessidade para uma ação futura. Novamente, a persuasão se faz presente por meio dos subentendidos:

- hoje você não precisa de Merthiolate;

- no futuro você pode vir a precisar;

- por isso, tenha sempre Merthiolate;

- você só vai usá-lo quando se machucar.

4) "SBT na nossa frente, só você."

A escolha da palavra «frente» permite algumas interpretações: na nossa frente: na nossa dianteira ou diante de nós. A polissemia não é acidental, pelo contrário, é o resultado de cuidadoso planejamento, uma vez que torna 
o texto ambíguo, permitindo diferentes leituras. Além do enriquecimento da mensagem, a mente do leitor trabalha na seleção dos significados. Observa-se, ainda, que quando há duas interpretações de um texto, sempre uma delas é dominante; e se ela não é a que interessa ao produto, a polissemia perde sua função e se converte em um erro tático de publicidade. No caso deste «slogan», as duas interpretações são importantes e interessam ao consumidor, pois:

- na frente do SBT só "você";

- você (telespectador) só vê o canal SBT.

Assim, os subentendidos são:

- O SBT está à frente dos concorrentes;

- Você só liga a televisão no SBT.

A coincidência de sons, assonância, (esse-be-te-você) dá cadência musical à mensagem, reforçando a informação. Mais uma vez, constata-se a presença do dêitico «você», criando uma assujeitamento na formação discursiva.

Como o enunciado publicitário tende a intervir persuasivamente no enunciatário com o propósito de modificar suas crenças e atitudes, a mensagem deve potencializar tal tendência, utilizando-se de elementos lingüísticos detentores de grande força semântica. É o caso do operador argumentativo «só» (apenas) que exclui do «slogan» qualquer outra significação. Assim, ele é o grande responsável pela argumentação ideológica do texto em questão.

5) "Nokia - o mundo todo só fala nele."

$\mathrm{O}$ «slogan» apresenta um enunciado que pertence à formação discursiva de um campo lexical de domínio público (telefone celular), em que o enunciatário atua como sujeito. A polissemia do verbo «falar» indica a ambigüidade do texto:

- o mundo todo só fala ao telefone Nokia;

- o mundo todo só fala a respeito do telefone Nokia.

Observa-se, também, o uso de recursos retórico-estilísticos: metonímias (marca pelo produto e singular pelo plural) e hipérbole (mundo «todo»), denotando valor coletivo da expressão, com o uso do pronome indefinido «todo» posposto ao substantivo. Os procedimentos acima não são usados de maneira aleatória, mas reforçam o ato de persuadir o leitor a comprar e a usar somente o produto em questão: Nokia. Os subentendidos também se fazem presentes:

- se todas as pessoas falam no celular Nokia é porque ele é o melhor;

- se todas as pessoas falam a respeito dele é porque ele é o melhor;

- se você faz parte do mundo (pessoas com celular), você deve comprar e usar somente o Nokia; 
- se você não faz parte do mundo (pessoas com celular), mas deseja fazer parte dele, você deverá comprar e usar o Nokia.

Novamente, há o uso do operador argumentativo só, enfatizando o poder de persuasão do «slogan», que é o de eliminar qualquer concorrente da empresa Nokia, pois esta é a melhor.

6) “Nó, daqui para frente, só na cabeça dos homens.” (nova linha de condicionadores Pantene)

No «slogan» em questão a metáfora também se faz presente: «nó na cabeça dos homens». A palavra «nó» apresenta duplo sentido, podendo ser:

- entrelaçamento feito na extremidade ou no meio do cabelo;

- dificuldade, intriga,

Por meio do primeiro sentido, argumenta-se sobre o produto (condicionador), mostrando a sua eficiência: não há formação de nó, o cabelo fica macio. O segundo sentido também prova a qualidade do produto, pois os homens se mostrarão intrigados pela beleza da mulher, proporcionada pelo uso do novo condicionador. A polissemia não só desperta curiosidade, como também provoca reflexão, criando alguns subentendidos, como:

- o condicionador Pantene não deixa nós nos cabelos;

- o condicionador Pantene deixa os cabelos macios;

- os homens querem saber por que os cabelos da mulheres estão sedosos.

O operador argumentativo «só», ou o determinante, segundo Oswald Ducrot, também permite duas leituras:

- somente quem usar o condicionador não terá nó na cabeça;

- somente os homens terão nó na cabeça, porque as mulheres estarão usando o condicionador.

Assim, o uso dos operadores demonstra a força argumentativa dos enunciados, apontando para determinada direção: persuadir o enunciatário para a compra do condicionador. A expressão "para frente» intensifica os aspectos positivos do produto, pois só a partir do momento em que ele for usado, os cabelos ficarão sem nó.

7) “Todos os caminhos conduzem a Visa.” (cartão de crédito)

A metonímia, novamente, faz-se presente (cartão de crédito), ao lado de uma outra estratégia argumentativa freqüente em publicidade: trata-se do «détournement», termo usado para designar alteração na forma e/ou no conteúdo de outro «slogan», provérbio ou frase feita. Esse recurso caracteriza-se por apresentar um caráter polifônico, já que o enunciado proposto remete a um outro, formulado por um enunciador diferente. No «slogan» em questão, a voz do enunciador genérico, representando a sabedoria popular, alude à expressão: «Todos os caminhos conduzem a Roma». Para compreender seu sentido, o enunciatário encontra a forma fixa que é ativada na sua memória (Roma $=$ Visa). Além disso, há a presença de outros recursos lingüísticos persuasivos: as palavras-chave (Roma e Visa) possuem o mesmo número de sílabas e são paroxítonas, 
contribuindo para a rápida fixação na mente do público.

Após a análise de alguns exemplos, acredita-se ter atingido o objetivo inicial, ou seja, comprovar o poder das estratégias argumentativas presentes no «slogan». Através de procedimentos de construção do discurso publicitário, pode-se afirmar que a publicidade é muito mais do que um mecanismo de venda; é um espelho da sociedade, na medida em que reflete valores sociais e reconstrói arquétipos do imaginário de todos. Embora o número de textos analisados não tenha sido exaustivo, pode-se concluir que:

- o «slogan» impõe, nas linhas e entrelinhas, valores, mitos e ideais, utilizando-se de recursos, sejam eles de natureza fonética, léxica, semântica ou morfossintática;

- o uso de citações e «détournement» desperta a adesão de algo já visto e ativa o conhecimento partilhado no leitor, criando uma espécie de cumplicidade;

- os enunciados componentes da mensagem, elaborados com figuras de retórica, potencializam a tendência de intervir persuasivamente no enunciatário (você), modificando suas crenças, atitudes e até sua identidade;

- o emprego de palavras polissêmicas gera no texto uma ambigüidade que não é acidental, mas resultante de rigorosa escolha lexical, de modo a permitir várias leituras e instaurar no texto os subentendidos;

- o sujeito da enunciação articula o seu discurso de modo a prevalecer a sua fala, utilizando-se de modalizadores, operadores argumentativos e indicadores atitudinais que marcam as intenções do locutor que, embora introduza nos enunciados estratégias de caráter polifônico, restringe as possibilidades do enunciatário.

Tomando por base o conceito de persuasão, verificou-se que o processo argumentativo aristotélico do discurso é o mesmo empregado atualmente na propaganda publicitária e, em específico, no «slogan», que funciona como uma rede de argumentos já conhecidos, embora nem sempre explicitados.

No presente trabalho, o enfoque foi apenas na natureza verbal do «slogan», mesmo sabendo da interdependência entre código verbal e não-verbal. Concluindo, os recursos lingüísticos freqüentes nos «slogans» corroboram para a venda do produto, intensificando a sua força persuasiva e despertando no indivíduo um mundo de magia.

"«O caminho fica aberto,

A quem mais quiser dizer

Pois eu mais não sei fazer... »".

(Cancioneiro Geral, Garcia de Resende)

\section{Bibliografia:}

ALTHUSSER, L. Ideologia e aparelhos ideológicos de Estado. São Paulo: Martins Fontes, 1974. 
BECHARA, Evanildo. Moderna Gramática Portuguesa. Ed. revista e ampliada. Rio de Janeiro: Lucerna, 1999.

BRANDÃO, Helena H. Nagamine. Subjetividade, argumentação, polifonia: a propaganda da Petrobrás. São Paulo: Unesp, 1998.

CARDOSO, Silvia Helena Barbi. Discurso e ensino. Belo Horizonte: Autêntica, 1999.

CARVALHO, Nelly. Publicidade: a linguagem da Sedução. São Paulo: Ática, 1996.

DUCROT, Oswald. Princípios de semântica lingüística. São Paulo: Cultrix, 1977.

GUIMARÃES, Helio de Seixas e LESSA, Ana Cecília. Figuras de linguagem: teoria e prática. 10ª ed. São Paulo: Atual, 1980.

KOCH, Ingedore G. Villaça. A interação pela linguagem. São Paulo: Contexto, 1992.

MAINGUENEAU, Dominique. Novas tendências em análise do discurso. $3^{\mathrm{a}}$ ed. Campinas: Pontes, 1997.

MARTINS, Jorge S. Redação Publicitária - Teoria e Prática. 2a ed. São Paulo: Atlas, 1977.

MICHAELIS. Moderno Dicionário de Língua Portuguesa. São Paulo: Melhoramentos, 1998.

MOSCA, Lineide do Lago Salvador. Retóricas de ontem e de hoje. São Paulo: Humanitas, 1999.

PERELMAN, C. Le champ de l'argumentation. Bruxelles: PUB, 1970.

REBOUL, Olivier. O slogan. São Paulo: Cultrix, 1977.

SANTANA, Armando. Propaganda: teoria, técnica e prática. $2^{\mathrm{a}}$ ed. São Paulo: Pioneira ,1977.

\section{Mini Currículo :}

Edson Santos Silva: Doutorando em Língua Portuguesa na FFLCH-USP. Professor de Língua Portuguesa e Literaturas, na UniSant'Anna e coordenador de oficinas pedagógicas. E-mail: jeremoabo@ig.com.br.

Wilma Rigolon: Mestre em Língua Portuguesa na PUC-SP e graduada em Pedagogia. Professora de Língua Portuguesa, Lingüística e Prática de Ensino nas Faculdades Integradas Teresa Martin/Uniesp. Coordenadora de oficinas pedagógicas. E-mail: wilma.rigolon@itelefonica.com.br. 